\title{
Using air, soil and vegetation to assess the environmental behaviour of siloxanes
}

\author{
N. $\operatorname{Ratola}^{1} \cdot$ S. $\operatorname{Ramos}^{1} \cdot$ V. Homem ${ }^{1} \cdot$ J. A. Silva ${ }^{1} \cdot$ P. Jiménez-Guerrero $^{2}$. \\ J. M. Amigo ${ }^{3}$ - L. Santos ${ }^{1}$ - A. Alves ${ }^{1}$
}

Published online: 20 April 2017

(C) Springer-Verlag Berlin Heidelberg 2017

\begin{abstract}
This study aimed to contribute to the enhancement of the knowledge of levels, trends and behaviour of eight siloxanes (four linear and four cyclic) in the environment. Adding to the prioritised scrutiny of the incidence in the atmosphere through passive samplers (sorbent-impregnated polyurethane foam disks - SIPs), the sampling of pine needles and soil was also performed, thus closing the circle of atmospheric exposure in the areas of study. Two sampling campaigns (one in summer and one in winter) were done in a total of eight sampling points in the Portuguese territory, which covered a wide range of human presence and land uses (urban, industrial, remote and beach areas). By adopting a "green" approach in terms of analytical methods, namely reducing the clean-up steps for the passive air samples and using the quick, easy, cheap, effective, rugged and safe (QuEChERS) technology for soils and pine needles, the results showed total concentration of siloxanes between 5 and $70 \mathrm{ng} \mathrm{g}^{-1}$ (dry
\end{abstract}

Responsible editor: Hongwen Sun

N. Ratola

nrneto@fe.up.pt

1 LEPABE-DEQ, Faculty of Engineering, University of Porto, Rua Dr. Roberto Frias, Porto, Portugal

2 Physics of the Earth, Regional Campus of International Excellence "Campus Mare Nostrum", University of Murcia, Edificio CIOyN, Campus de Espinardo, 30100 Murcia, Spain

3 Department of Food Science, Spectroscopy and Chemometrics, Faculty of Sciences, University of Copenhagen, Rolighedsvej 30, 1958 Frederiksberg C, Denmark weight) for soils and from 2 to $118 \mathrm{ng} \mathrm{g}^{-1}$ (dry weight (dw)) for pine needles, with no clear seasonal trend. For SIPs, the levels varied from 0.6 to $7.8 \mathrm{ng} \mathrm{m}^{-3}$ and were higher in summer than in winter in all sites. Overall, the cyclic siloxanes were found in much higher concentrations, with D5 and D6 being the most predominant in a great majority of cases. Also, the urban and industrial areas had the highest incidence, suggesting a strong anthropogenic fingerprint, in line with their main uses.

This article was originally intended as an invited contribution to the special issue Biomonitoring of atmospheric pollution: possibilities and future challenges but was inadvertently published prematurely in Environmental Science and Pollution Research Volume 23, Issue 4, pp. 3273-3284, DOI 10.1007/s11356-015-5574-4. 